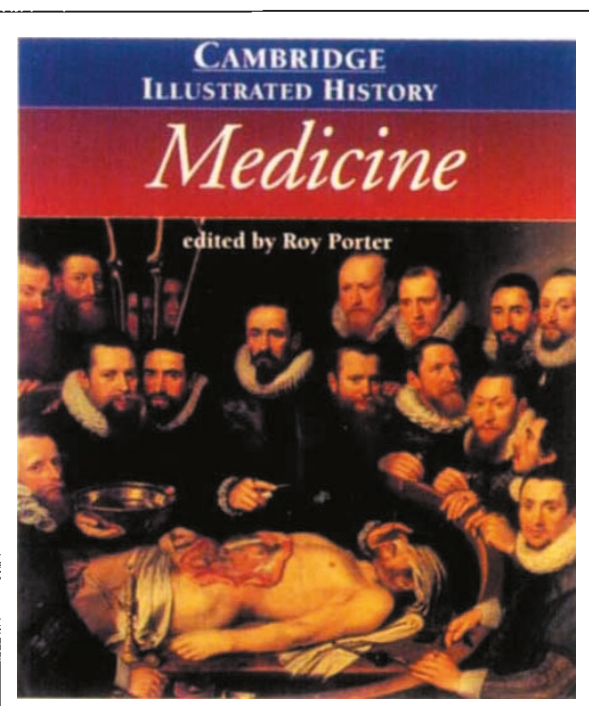

\section{The Cambridge Illustrated History of Medicine}

\author{
edited by Roy Porter \\ Cambridge University Press \\ ISBN: 0521442117, 1996, \$39.95
}

\section{Reviewed by James J. Ferguson, JR. Professor Emeritus \\ University of Pennsylvania \\ Chevy Chase, Maryland 20815, USA}

For a nonhistorian physician, reading traditional books on medical history can at times be daunting. Too frequently I associate such reading with ponderousness, obscure footnotes, scholarly detachment, and musty boredom. The Cambridge Illustrated History of Medicine wonderfully changes that. It is an imposing publication, skillfully escaping such features which so frequently contaminate the pleasures of historical reading. This is a rich, stylish, and content-laden book, easily read and easily digested. It emphasizes always the perspective that helps us understand the complexities that have determined the configuration and content of today's healing arts and sciences. It is, in Professor Porter's words, "essentially a history of the roots, rise, and present state of the major specialties of Western medicine, or, as it might be called, scientific medicine." It is written for an audience much broader than that of physicians and other health providers. But this in no way detracts from its appeal - in fact it embellishes it by broadening its perspectives. It has a slight but fully understandable tilt toward British medicine, again without significant impediment. I was deeply into the book before even noticing those tiny numbers that referenced footnotes in the rear. However, there is a rich (but discreetly concealed) annotation for those prompted to further exploration. The many medical systems which have emerged in the non-Western world receive scant mention. While this, to an extent, invalidates the scope of the book's title, it certainly adds to its portability, if not its focus.

In structure, The Cambridge llustrated History of Medicine comprises a series of essays on ten major aspects of medicine, written by Roy Porter and six of his colleagues. One might visualize blind men describing an elephant, but these are not blind men! They are wonderfully perceptive commentators, and they almost seamlessly integrate their individual essays into the whole of the book. Their topics include The History of Disease; The Rise of Medicine; What is Disease?; Primary Care; Medical Science; Hospitals and Surgery; Drug Treatment and the Rise in Pharmacology; Mental Illness; Medicine, Society, and the State; and Looking to the Future. Each topic is presented with an emphasis on the social, political and scientific factors which have influenced "medical progress". There is no preachiness, and no villains are blamed for events. Rather the authors provide a comfortably detached exposition on how things came to be, this generally with deft literary style. To dwell briefly on but one of these essays, Porter's own chapter on mental illness recounts the ebb and flow of thought on the causation and management of mental disorders. Changing concepts of etiology, such as the derangement of reason, unbalanced "humors," demonic and sacred possession, fanaticism, stress, and perversion have led to comparably bizarre means of treatment. In the course of time, some of the afflicted were revered, some shunned, some confined in isolation, some chemically purged or electrically shocked, and some, more recently, "decarcerated." Even today the classification of mental diseases is tantalizing in its uncer- tainty. Porter concludes appropriately that the volatility in the history of these disorders dictates caution in the extreme when we judge the validity of our current perceptions and handling of mental disorders.

The book is laced with an eclectic assortment of illustrations, some shocking, some whimsical, some artistic, but all smoothly integrated into the thrust of the overall historical message. There are rare and minute technical mistakes (the Mayo Clinic is not in Rochester, New York!) but the enormity of the message easily dilutes these slips to insignificance. It's certain that some historians with bona fide credentials will dispute aspects of contextual detail, but then history, like beauty, is usually defined by the eyes (or imagination) of its narrator.

Quotations abound, each contributing a flavor to the perception of events. "Let not the sun go down behind the hill without your having gone out, or if you cannot, take before meals a little exercise ... and it would help you to drink, a quarter of an hour before your repast, a full half-glass of good red wine, neither too dry nor too sweet." These words should warm the soul of today's noninterventional cardiologist, but, unfortunately, they constitute advice provided in the year 1401 by one Lapo Mazzei on how to avoid the plague. Would a draught of statins have helped? Perhaps.

Mercifully, one finds but a lone comment on Health Maintenance Organizations, and none relating to today's more trendy manifestations such as managed care, quality scores, "gag" contracts, and the like. Rather, there is a detailed dissection of the very broad and complex social, religious, political and scientific factors that have brought us to what we perceive to be modern medicine. Particularly provocative is commentary on the appeal of nontraditional forms of medical care, a phenomenon which, of course, has been with us through the centuries and shows no sign of abatement.

Would that I could be preserved by encasement in amber, or by some other such mechanism, so that I could return several centuries from now to read of the fate of the "usual and customary" perceptions by which we currently define medicine. I only hope that such a future history will be compiled by persons comparable in skill to those who assembled this very attractive book. 